\title{
Evaluación de métodos para la separación eficiente de leucocitos
}

\author{
Johanna De Castro', María Orfa Rojas ${ }^{1}$, Moisés Wasserman²
}

\begin{abstract}
Resumen
En el uso de métodos diagnósticos para parásitos de malaria, basados en PCR sobre sangre completa, la presencia de leucocitos causa frecuentemente interferencias que pueden llegar a enmascarar completamente los resultados. Para eliminar este problema, se probaron diferentes metodologías para la remoción de células blancas de la sangre total, basados en las densidades y tamaños de los componentes sanguíneos; para controlar la remoción, se utilizó la reacción en cadena de la DNA polimerasa con iniciadores arbitrarios, RAPD. La alta sensibilidad de este método nos permitió definir con una buena precisión que la filtración de la sangre a través de una columna de celulosa-sephadex G-25 permite las mejores remociones, si se compara con otras matrices o con separaciones a través de ficoll, dextrán o ficoll-dextrán.
\end{abstract}

\section{Summary}

In the use of diagnostic methods for malaria parasites, based on polymerase chain reaction (PCR) in whole blood, leucocyte presence frequently causes interference which can completely mask results. In order to avoid this problem, different methods were tested to eliminate leucocytes from whole blood, based on the density and size of blood components. This elimination procedure was controlled by DNA polymerase chain reaction using arbitrary primers (RAPD). This method's high sensitivity allowed us to accurately define that whole blood's filtration through a cellulose-sephadex G-25 column allows the best elimination, compared to other matrices or separation methods such as ficoll, dextran or ficoll-dextran.

En estudios bioquímicos o moleculares de parásitos intracelulares es indispensable distinguir qué actividades corresponden a la célula huésped y cuáles al parásito. Esta situación crea la necesidad de separar los componentes celulares, pues, de seguir mezclados se vería afectada la validez de los datos experimentales.

En el caso de Plasmodium falciparum, por ejemplo, en cualquier método diagnóstico que utilice técnicas tan sensibles como la reacción en cadena de la DNA polimerasa, la presencia de contaminaciones traza de DNA humano constituye una interferencia de tal magnitud que puede llegar a enmascarar el resultado esperado (1).

Tradicionalmente, se han empleado diversas estrategias para la separación de células blancas de la sangre completa; estas estrategias se basan en la densidad de las diferentes células de la sangre, afinidades específicas de las células por diferentes soportes, propiedades de adhesión, etc. La técnica más utilizada ha sido la separación de células en colchones y gradientes de densidad como el ficoll, el dextrán y el percoll (2-6). También, con menos éxito, se ha utilizado el fibrinógeno y las fitohemaglutininas (3). Sin em-

Grupo de Bioquímica, Instituto Nacional de Salud, Santa Fe de Bogotá, Colombia.

2 Grupo de Bioquímica Instituto Nacional de Salud y Facultad de Ciencias, Universidad Nacional de Colombia, Santa Fe de Bogotá, Colombia. 
bargo, el principal inconveniente en la aplicación de la metodología tradicional de separación de componentes sanguíneos radica en que su enfoque va dirigido a la recuperación de células blancas y a la eliminación de células rojas, sin importar si hay lisis de estas últimas. En nuestro caso, se necesita conservar la célula roja intacta -por ser hospedera del parásito en estudio- y libre de los otros componentes sanguíneos por las razones anotadas anteriormente.

Se han diseñado otras estrategias más modernas de separación mediante cromatografías de afinidad, utilizando diferentes anticuerpos contra los antígenos de superficie de las células blancas (5-7); sin embargo, estas técnicas permiten la separación de poblaciones específicas de glóbulos blancos y desechan las células rojas.

En 1976, Beutler mencionó la utilización que, desde 1928, se hacía del algodón para remover leucocitos de la sangre (8). Esta fue la metodología seguida durante muchos años para preparar concentrados de células rojas con remoción parcial de células blancas para transfusión y la base para el desarrollo del método utilizado por ellos. Estos autores compararon las eficiencias de columnas empacadas con diferentes tipos de celulosa e informaron haber obtenido los mejores resultados con una mezcla de celulosa microcristalina-sephadex G-25, en relación 3:1 ( $\mathrm{v} / \mathrm{v})$.

En este estudio, se probaron varios métodos de separación de células blancas de la sangre total teniendo en cuenta básicamente las diferencias de densidades y tamaños de los componentes de la sangre; la eficiencia de cada proceso se evaluó mediante la reacción en cadena de la DNA polimerasa con iniciadores arbitrarios (RAPD), que es una técnica de altísima sensibilidad y en cuya aplicación surgió el problema de interferencia que nos ocupa.

\section{Materiales y métodos}

\section{Remoción de leucocitos de la sangre}

1.Centrifugación en colchones de densidad constante
Se recolectó $1 \mathrm{~mL}$ de sangre, tipo $\mathrm{O} R \mathrm{R}+$, por punción venosa, utilizando CPD-A3, (15 mM ácido cítrico, $90 \mathrm{mM}$ citrato de sodio, $16 \mathrm{mM}$ fosfato de sodio monobásico, $250 \mathrm{mM}$ dextrosa, $4 \mathrm{mM}$ adenina, $\mathrm{pH} 5,9$ ), como anticoagulante. La sangre fresca se centrifugó a $200 \times g$ (Centrífuga International, modelo $\mathrm{HN}$, rotor 215), a temperatura ambiente, durante 10 minutos para eliminar el plasma, y mediante un conteo en cámara de Neubauer, se determinó el contenido de células blancas totales. Las células rojas sedimentadas se resuspendieron $\mathrm{v} / \mathrm{v}$ en $\mathrm{HBS}(160 \mathrm{mM} \mathrm{NaCl}, 20$ mM HEPES ácido, $\mathrm{pH} 7,4)$ y se adicionaron suavemente por las paredes de un tubo de 2 $\mathrm{mL}$, sobre un colchón de $1 \mathrm{~mL}$ de ficoll (Pharmacia) (4) o de dextrán (Sigma) (3); se ensayó, además, un lavado consecutivo con ficoll-dextrán en las mismas condiciones mencionadas anteriormente. Después de descartar el sobrenadante que contenía las células blancas, se lavaron las células rojas dos veces con HBS. Finalmente, se calculó el porcentaje de remoción por conteo de células en cámara de Neubauer.

2.Filtración a través de columnas de algodón en rama, algodón comercial-Alfitex y celulosa microcristalina mezclada con sephadex G-25

El algodón se sumergió en $\mathrm{NaCl} 0,15 \mathrm{M}$ y se esterilizó en autoclave por 20 minutos a 15 libras de presión por pulgada cuadrada. La celulosa y el sephadex se hidrataron por separado en $\mathrm{NaCl}$ 0,15 $\mathrm{M}$ durante 24 horas a temperatura ambiente; se mezclaron en relación $3: 1(\mathrm{v} / \mathrm{v})$ y se utilizaron para empacar columnas con un volumen de matriz de $4 \mathrm{~mL}$ en jeringas de $5 \mathrm{~mL}$ (8). Sobre la columna, se agregó $1 \mathrm{~mL}$ de sangre venosa fresca anticoagulada con CPD-A3, a la cual previamente se le había hecho un recuento de glóbulos blancos. La elución de las células se hizo con $10 \mathrm{~mL}$ de $\mathrm{NaCl}$ 0,15 M mediante presión ejercida con el émbolo de la jeringa; este proceso de filtración debe durar aproximadamente 10 minutos (8, 10). Finalmente, las células eluidas, se centrifugaron a $200 \times g$ (Centrífuga International, modelo $\mathrm{HN}$, rotor 215) para eliminar el exceso de eluyente y mediante un nuevo recuento de 
leucocitos (cámara de Neubauer) se calculó el porcentaje de remoción.

\section{Ensayo de RAPD para confirmar la remoción de leucocitos}

Para confirmar la remoción efectiva de leucocitos, se tomaron las células rojas empacadas, obtenidas por centrifugación o filtración, y se lisaron con saponina $0,15 \%$ en HBS, por 10 minutos a $37^{\circ} \mathrm{C}(11)$; los lisados se lavaron dos veces con HBS y se trataron por 24 horas a $60^{\circ} \mathrm{C}$ con $0,01 \mathrm{M}$ EDTA, pH $8,0,01 \mathrm{M}$ tris $\mathrm{HCl}, \mathrm{pH} 8,0,1 \%$ tritón $\mathrm{X}-100$ y $0,2 \mathrm{mg} / \mathrm{mL}$ proteinasa $\mathrm{K}$, para permitir la digestión de proteínas, la lisis de los glóbulos blancos y la liberación del DNA humano, en el caso de la permanencia de células leucocitarias después del tratamiento aplicado. Como control positivo en la reacción de amplificación, se utilizó sangre anticoagulada con CPD-A3 sin ningún tratamiento previo $\mathrm{y}$, como control negativo, una muestra sin DNA. Con los extractos crudos, se llevaron a cabo ensayos de RAPD, de acuerdo con el método estandarizado previamente (1); brevemente, los perfiles de temperatura incluyeron una denaturación inicial a $95^{\circ} \mathrm{C} / 5 \mathrm{~min}$, 10 ciclos de denaturación a $95^{\circ} \mathrm{C} / 1 \mathrm{~min}$, anillaje a $20^{\circ} \mathrm{C} / 1 \mathrm{~min}$ con un incremento de la temperatura de $1^{\circ} \mathrm{C} / \mathrm{min}$ hasta alcanzar la temperatura de extensión de $50^{\circ} \mathrm{C} / \mathrm{min}$; posteriormente, se hicieron 20 ciclos en los cuales el anillaje se hizo a $25^{\circ} \mathrm{C} / \mathrm{min}$ con un incremento de temperatura de $6^{\circ} \mathrm{C} / \mathrm{min}$ hasta alcanzar la de extensión. Finalmente, se terminó con una extensión a $72^{\circ} \mathrm{C} / 10 \mathrm{~min}$. Como iniciador en la reacción de amplificación, se utilizó un oligonucleótido de 10 bases (R3) previamente diseñado por nosotros (5'GGCTACATCA-3')(1). Las muestras amplificadas se corrieron en geles de poliacrilamida $4 \%$-úrea $7 \mathrm{M}$ a $100 \mathrm{~V}$ por 4 horas y se tiñeron con plata de acuerdo con el protocolo previamente descrito (1).

\section{Resultados}

\section{Centrifugación en medios de densidad constante}

Los resultados para los dos colchones de densidad constante utilizados fueron muy similares; microscópicamente, se detectó la presencia de células polimorfonucleares y una remoción máxima del $81 \%$. Al utilizar la secuencia ficoll-dextrán, la eficiencia de remoción no aumentó significativamente y el máximo de remoción alcanzado fue de $82 \%$. La detección de las células blancas que permanecieron después del ensayo, mediante el RAPD, se muestra en la figura 1. En los carriles 3-8, se amplificaron los lisados de las muestras provenientes de los diferentes tratamientos $y$, en los carriles 1 y 2 , la sangre que no fue sometida a ningún tratamiento; en todos los casos, la amplificación fue similar y permitió detectar el DNA contaminante.

\section{Filtración a través de diferentes matrices}

En el caso de la filtración en columnas de algodón comercial, algodón en rama y la mezcla celulosa microcristalina-sephadex G-25, los porcentajes de remoción varían entre $80 \mathrm{y}$, aproximadamente, $100 \%$, respectivamente. EI resultado con el algodón fue similar al obtenido con los colchones de densidad constante; sin embargo, el algodón en rama mostró una mayor retención de células blancas. De manera similar, la celulosa utilizada como matriz permitió remociones cercanas al $100 \%$. Para corroborar los resultados microscópicos o, en otras palabras, detectar con una máxima sensibilidad la permanencia del DNA proveniente de células blancas en los eritrocitos después de cada tratamiento, se realizó el ensayo de RAPD. En la figura 2, se observa el resultado de la amplificación de los lisados de la sangre filtrada en columnas de algodón; como se puede observar, el patrón de amplificación generado por estas muestras corresponde al del DNA humano. Comparando los resultados del RAPD para las muestras provenientes de los colchones y para las muestras provenientes de las columnas de algodón se estableció que la contaminación con DNA humano persiste y que todos los resultados muestran un patrón similar de amplificación entre sí y con la sangre completa (sin ningún tratamiento) usada como control positivo. Al amplificar el lisado de la sangre filtrada a través de columnas de celulosa microcristalina-sephadex G-25, no se pudo 
Figura 1. Un $\mathrm{mL}$ de sangre completa y fresca se preparó como se describe en materiales y métodos. Se pasó a través de los diferentes colchones y se lisó con saponina. Un microlitro de este lisado se sometió a amplificación por RAPD (1-2), sangre completa sin pasar por el colchón, utilizada como control (3-4), sangre pasada por colchón de ficoll (5-6), sangre pasada por dextrán (7-8), sangre pasada por ficolldextrán (9), 3,5 $\mu \mathrm{g}$ DNA humano usado control positivo (10), 500 ng DNA Ladder $1 \mathrm{~kb}$ usado como marcador de tamaño.
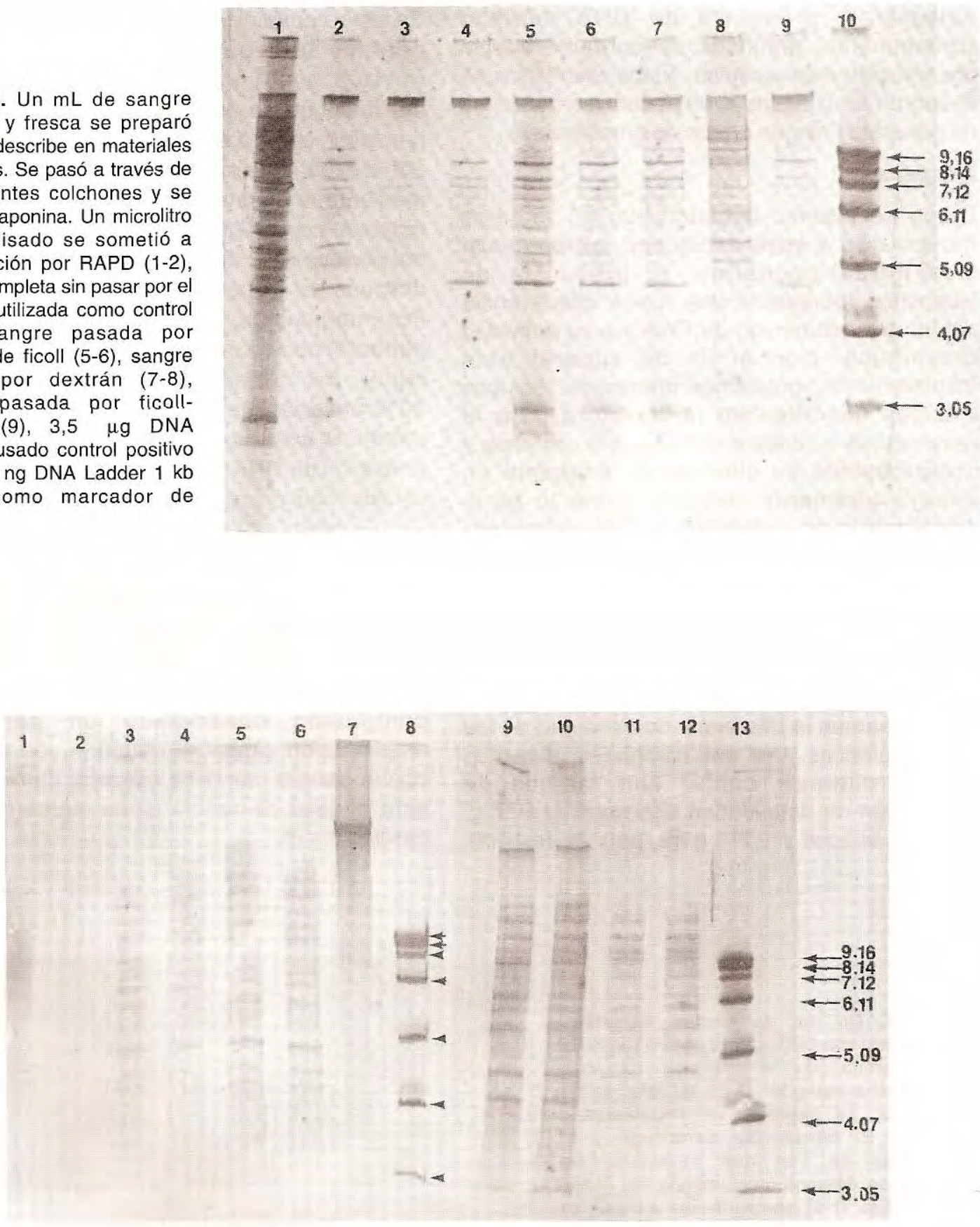

Figura 2. Dos $\mathrm{mL}$ de sangre completa se prepararon como se describe en materiales y métodos; $1 \mathrm{~mL}$ se pasó a través de una columna de $4 \mathrm{~mL}$ de algodón en rama y el otro por una columna de $4 \mathrm{ml}$ de algodón comercial. Después de la filtración, los eritrocitos se lisaron con saponina y de este lisado se tomaron alícuotas para la amplificación. Cada punto se hizo por duplicado. (1-6), sangre filtrada a través de algodón en rama; (1-2), $1 \mu \mathrm{L}$ del lisado; $(3-4), 5 \mu \mathrm{L}$ del lisado y (5-6) $10 \mu \mathrm{L}$ del lisado; (7) 3,5 $\mu \mathrm{g}$ DNA humano usado control positivo; (9-12), sangre filtrada a través de algodón comercial; (9-10), $5 \mu \mathrm{L}$ del lisado y (11-12), $1 \mu \mathrm{L}$ del lisado. (8) y (13) $500 \mathrm{ng}$ DNA Ladder $1 \mathrm{~kb}$ utilizado como marcador de tamaño. 
detectar la presencia de DNA humano contaminante, resultado concordante con la observación microscópica. Estos resultados se observan en la figura 3, en la cual las muestras no generaron ningún patrón de amplificación.

\section{Discusión}

Como se planteó inicialmente, en trabajos moleculares o enzimáticos con microorganismos intraeritrocitarios, la presencia de leucocitos representa una fuerte interferencia debido a su contenido de DNA y a su actividad bioquímica. Con el fin de superar este inconveniente, probamos diferentes técnicas clásicas descritas en la literatura para la remoción de leucocitos de la sangre completa y comprobamos su eliminación mediante un ensayo altamente sensible como lo es la amplificación en cadena de la DNA polimerasa con iniciadores arbitrarios, RAPD. La sangre completa extraida de un paciente está constituida por una población heterogénea de células blancas desde el punto de vista de sus características físicas como la morfología y la densidad. En la primera estrategia empleada, aprovechamos la diferencia de densidad de las células blancas. Los dos colchones utilizados nos permitieron contar con medios de separación de densidades diferentes $(1,077 \mathrm{~g} /$ $\mathrm{mL}$ para el ficoll y $1,113 \mathrm{~g} / \mathrm{mL}$ para el dextrán).
En estas condiciones, el colchón de ficoll nos permitió la separación de mononucleares $(\mathrm{d}=1,06 \mathrm{~g} / \mathrm{mL})$ y plaquetas $(\mathrm{d}=1,04 \mathrm{~g} / \mathrm{mL})$, mientras que los polimorfonucleares $(1,09 \mathrm{~g} / \mathrm{mL})$ precipitan con los eritrocitos que son agregados por el ficoll. Esta situación se reflejó claramente mediante el ensayo de RAPD, donde el patrón obtenido con el DNA humano usado como control positivo es similar al patrón de las muestras después del tratamiento (figura 1, carriles 1-4). Por microscopía, se pudo determinar que la remoción no superó nunca el $80 \%$ (el ensayo se repitió, por lo menos, 7 veces) y, por tanto, el $20 \%$ restante fue suficiente para mostrar un patrón de amplificación o, en otras palabras, la presencia de DNA humano contaminante en las células rojas procesadas.

El dextrán funciona bajo el mismo principio o fundamento que el ficoll, pero con otra densidad, que cubre la población celular que escapa al ficoll. Sin embargo, aunque comparativamente disminuía la población de polimorfonucleares, la remoción no superó el $80 \%$ por lo cual se continuaba observando un patrón de amplificación similar al obtenido con el ficoll y con la sangre completa utilizada como control; este ensayo se repitió cinco veces (figura 1 , carriles 5 y 6 ).
Figura 3. Un $\mathrm{mL}$ de sangre completa, anticoagulada con CPD-A3, se pasó a través de una columna de $4 \mathrm{~mL}$ de celulosa microcristalina-sephadex G-25, en relación 3:1 $(\mathrm{v} / \mathrm{v})$ como se describe en materiales y métodos. El filtrado se centrifugó y el precipitado se lisó con saponina. Se amplificaron diferentes volúmenes del lisado por duplicado. (1-4), sangre filtrada a través de celulosa-sephadex; (1-2), $1 \mu \mathrm{L}$ del lisado y (34), $5 \mu \mathrm{L}$ del lisado; (5-6), sangre completa sin filtrar, utilizada como control positivo. (7) muestra sin DNA utilizado como control negativo, (8) 500 ng DNA Ladder $1 \mathrm{~kb}$ utilizado como marcador de tamaño.

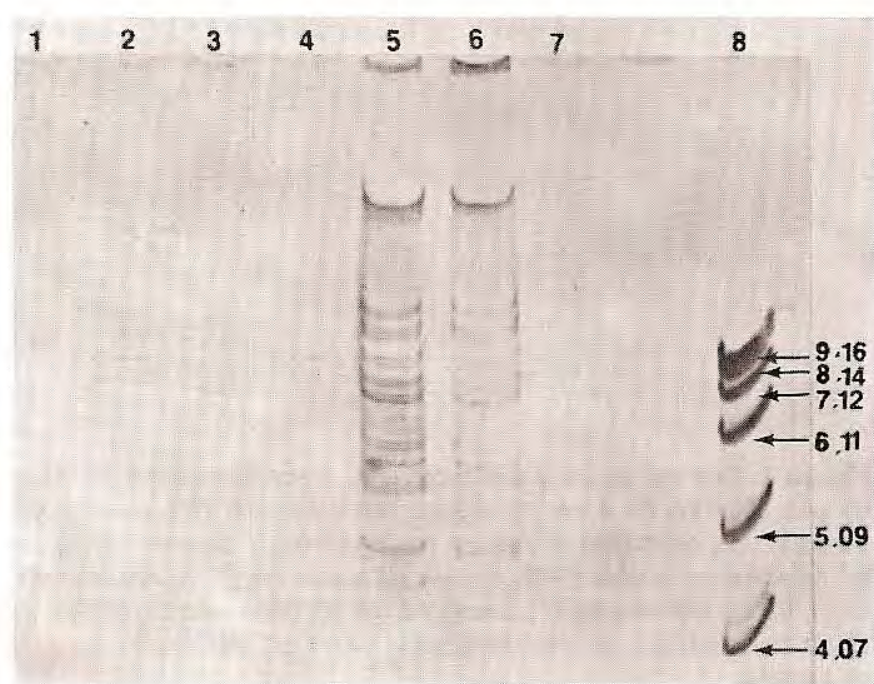


Finalmente, la utilización ficoll-dextrán, con miras a una separación secuencial mononucleares-polimorfonucleares no aumentó la remoción y, microscópicamente, se pudo establecer que muchos más polimorfonucleares escaparon al colchón, posiblemente porque este tipo de células, a la presión osmótica ligeramente aumentada del ficoll, pierden agua y aumentan su densidad lo que les permite migrar a través de él y, tal vez, también a través del dextrán (figura 1, carriles 7 y 8) (12).

Para la segunda estrategia de filtración en columna, empacada con celulosa de diferente concentración y pureza, el fundamento se basa en que este material es capaz de unir las células blancas mediante interacción débil, mecanismos de adhesión e impedimento mecánico. Los mecanismos pueden combinarse y células como los polimorfonucleares pueden adherirse indirectamente por agregación entre ellas o por unión a factores plaquetarios. Como factor importante en estas consideraciones, se tomó la diferencia en diámetro de las poblaciones celulares sanguíneas que, exceptuando los basófilos y los eritrocitos, están entre $10-20 \mathrm{~mm}$. Para evitar que algunos eritrocitos se queden atrapados en la columna, se aumentó el volumen de elución de glóbulos rojos utilizando $10 \mathrm{~mL}$ de $\mathrm{NaCl} 0,15 \mathrm{M}$ por cada mililitro de sangre. Por otra parte, es posible que algunos basófilos escapen a la retención por parte de la columna, pero, tanto las interacciones indirectas como su escasa presencia en la sangre total (0-1\%) permiten despreciar la contaminación que puedan generar.

Las columnas de algodón, que en su forma más pura contiene $90 \%$ de celulosa, mostraron una remoción semejante a la obtenida con el ficoll y el dextrán. Al realizar la amplificación de estos lisados, se observó cómo la contaminación con DNA humano era detectada como un patrón de bandas similar al control positivo (figura 2 , carriles $1-6$ y $9-12$ ).

Se utilizó, además, la celulosa microcristalina comercial, sustancia blanca, insoluble en agua u otros solventes usuales, según el método descrito en (8). Esta celulosa tiene forma de barras rígidas que se hidratan en agua y se usa comúnmente en cromatografía en columna y en capa fina. La celulosa microcristalina se mezcló en proporción 3:1 v/v con sephadex G-25 cuyo diámetro de partícula oscila entre 20 y $50 \mathrm{~mm}$ cuando está hidratado y cuya finalidad es funcionar como espaciador de las partículas de celulosa. Con esta columna, la remoción alcanzó valores de $100 \%$ por examen microscópico. Aunque en el ensayo microscópico puede haber subjetividad, los ensayos de amplificación por RAPD no mostraron el patrón correspondiente a la presencia de DNA humano; el ensayo fue repetido, por lo menos, 20 veces (figura 3, carriles 1-4). Es muy importante controlar el tiempo de filtración ya que la interacción celulosa-glóbulos blancos es débil y los tiempos prolongados de filtración facilitan la liberación de las células unidas a la matriz. La literatura informa la utilización de diversos filtros que, bajo el mismo principio, remueven glóbulos blancos de la sangre completa para evitar complicaciones transfusionales (9); este tipo de material posiblemente permite eficiencias mayores; sin embargo, en este estudio no disponíamos de estos materiales para efectuar el ensayo.

En este estudio, el método de remoción de leucocitos de la sangre a través de columnas de celulosa-sephadex mostró los mejores resultados y ha sido ensayado hasta ahora con muestras simuladas en el laboratorio para detectar polimorfismo genómico en Plasmodium falciparum. Posteriormente, se probará con muestras clínicas de pacientes maláricos, en las cuales se pretende estudiar la heterogeneidad de la población circulante de parásitos en áreas endémicas.

\section{Referencias}

1. Rojas MO, De Castro J, Mariño G, Wasserman M. Detection of genomic polymorphism in Plasmodium falciparum using an arbitrarily primed PCR assay. J Euk Microbiol 1996;43:323.

2. Perper RJ, Zee TW, Mickelson MM. Purification of lymphocytes and platelets by gradient centrifugation. J Lab Clin Meth 1968;72:842.

3. Skoog WA, Beck WS. Studies on the fibrinogen, dextran and phytohemagglutinin methods of isolating leukocytes. Blood 1956;11:436.

4. Ferrante A, Thong YH. Optimal conditions for simultaneous purification of mononuclear and polymorpho- 
nuclear leukocytes from human blood by the hypaqueficoll method. J Immunol Meth 1980;36:109.

5. Best CL, Pudney J, Anderson DJ, Hill JA. Modulation of human granulosa cell steroid production in vitro by tumor necrosis factor alpha: implications of white blood cells in culture. Obstet Gynecol 1994;84:121.

6. Ramos RR, Curtis BR, Duffy BF, Chaplin H. Low retention of white cell fragments by polyester fiber white reduction platelet filters. Transfusion 1994;34:31.

7. Best CL, Griffin PM, Hill JA. Interferon gamma inhibits luteinized human granulosa cell steroid production in vitro. Am J Obstet Gynecol 1995;172:1505.

8. Beutler E, West C, Blume KG. The removal of leukocytes and platelets from whole blood. J Lab Clin Med 1976;88:328.
9. Steneker I, van Luyn MJA, van Wachem PB, Biewenga J. Electronmicroscopic examination of white cell reduction by four white cell-reduction filters. Transfusion 1992;32:450.

10. Nakao M, Nakayama T, Kankura T. A new method for separation of human blood components. Natural New Biol 1973;246:94.

11. Goman M, Langstey G, Hyde JE, Yankovsky NK, Zolg JW, Scaife JG. The establishment of genomic DNA libraries for the human malaria parasite Plasmodium falciparum and identification of individual clones by hybridisation. Mol Biochem Parasitol 1982;5:391.

12. Fotino M, Merson EJ, Allen FM. Micromethod for rapid separation of lymphocytes from peripheral blood. Ann Clin Lab Sci 1971;1:131. 